\title{
A ATIVIDADE JURISDICIONAL NA JUSTIÇA DO TRABALHO: A SENTENÇA UBER
}

\author{
JUDICIAL ACTIVITY IN THE LABOR COURT: THE UBER VERDICT
}

\section{LA ACTIVIDAD JURISDICCIONAL EN LA JUSTICIA DEL TRABAJO: LA SENTENCIA UBER}

\section{José Filomeno de Moraes Filho'}

\section{Carolina Nobre Castello Branco²}

Licença CC BY:

Artigo distribuído sob os termos Creative Commons, permite uso e distribuição irrestrita em qualquer meio desde que o autor credite a fonte original.

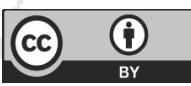

\begin{abstract}
Resumo: Este artigo tem como finalidade analisar sentença judicial proferida pela $33^{a}$ vara do trabalho no Brasil que reconheceu a existência de relação de emprego entre ex-motorista e a empresa UBER. Mediante a análise da atividade jurisdicional no constitucionalismo contemporâneo, procurou-se compreender o fenômeno do ativismo judicial para então estudar o a decisão judicial, permitindose a compreensão dos critérios de decisão. A pesquisa se desenvolve pelo método dialético, a partir de análise documental da sentença judicial confrontada com os argumentos teóricos encontrados em artigos científicos e doutrinas nacionais e estrangeiras, em especial a doutrina de Friedrich Müller. Como resultado, concluiuse que a decisão, apesar de coerente com a proteção esperada da Justiça do Trabalho, extrapolou os critérios jurídicos de argumentação e interpretação, sobretudo quanto aos limites do poder jurisdicional no exercício de sua função no Estado Democrático de Direito.
\end{abstract}

Palavras-chave: Uber; Ativismo judicial; Interpretação; Metódica; Jurisdição

Abstract: This paper aims to analyze a judicial sentence handed down by the 33rd labor court in Brazil that recognized the existence of an employment relationship between a formal Uber driver and the company. Through the analysis of jurisdictional activity in contemporary constitutionalism, it sought to understand the phenomenon of judicial activism and then to study the judicial decision, allowing the understanding of the decision criteria. The research was developed using the dialectical method, based on documentary analysis of the judicial sentence confronted with the theoretical arguments found in scientific papers and national and foreign doctrines, especially the doctrine of Friedrich Müller. The paper concludes that the decision, despite being consistent with the expected protection by the Labor Court, went beyond the legal criteria of argumentation and interpretation, especially regarding the limits of jurisdictional power in the exercise of its function in the Democratic Rule of Law.

\footnotetext{
1 Doutor em Direito pela USP. Professor Titular do Programa de Pós-Graduação em Direito Constitucional na UNIFOR. Procurador do Estado do Ceará. Fortaleza, Ceará, Brasil. E-mail: filomenomoraes@uol.com.br

2 Doutoranda em Direito Constitucional na UNIFOR. Mestre em Direito do Estado pela PUC-SP. Especialista em Direito Processual Civil pela PUC-SP. Advogada. Manaus, Amazonas, Brasil. E-mail: carolinancb@gmail.com
} 
Keywords: Uber; Judicial Activism; Interpretation; Methodical; Adjudication.

Resumen: Este artículo tiene como finalidad analizar la sentencia judicial proferida por la $33^{a}$ jurisdicción del trabajo en Brasil que reconoció la existencia de relación de empleo entre ex-conductor y la empresa UBER. Mediante el análisis de la actividad jurisdiccional en el constitucionalismo contemporáneo, se buscó comprender el fenómeno del activismo judicial para entonces estudiar la decisión judicial, permitiéndose la comprensión de los criterios de decisión. La investigación se desarrolló por el método dialéctico, a partir del análisis documental de la sentencia judicial confrontada con los argumentos teóricos encontrados en artículos científicos y doctrinas nacionales y extranjeras, en especial la doctrina de Friedrich Müller. Como resultado, se concluye que la decisión, a pesar de coherente con la protección esperada de la Justicia del Trabajo, extrapoló los criterios jurídicos de argumentación e interpretación, sobretodo cuanto a los límites del poder jurisdiccional en el ejercicio de su función en el Estado Democrático de Derecho.

Palabras clave: Uber; Activismo judicial; Interpretación; Metódica; Jurisdicción.

\section{INTRODUÇÃO}

O objetivo deste estudo é realizar uma análise da sentença judicial trabalhista que reconheceu vínculo de emprego entre ex-motorista e a empresa de tecnologia Uber.

Proferida pelo juiz da $33^{a}$ vara do trabalho de Belo Horizonte, a sentença foi a primeira do Brasil a reconhecer a existência de relação de emprego e, em razão da novidade do serviço prestado e do momento de expansão da empresa no território nacional, fomentou debates, sobretudo entre simpatizantes e usuários do aplicativo.

Do ponto de vista jurídico, a sentença representou um marco no reconhecimento de um vínculo jurídico de emprego pautado em relações sociais modificadas com o avanço da tecnologia. Na perspectiva acadêmica, serve como modelo para avaliar a construção da decisão jurídica a partir de parâmetros estabelecidos pelo direito, mas que precisam ser acomodados a novos fatos sociais.

Portanto, neste estudo interessa a perspectiva acadêmica, pois intenta analisar a sentença como a expressão do caminho percorrido pelo juiz para a construção de sua decisão. Desse modo, o foco principal é a análise dos critérios utilizados pelo juiz no exercício da sua atividade jurisdicional, com o objetivo de relacionar os fundamentos da decisão com fenômeno do ativismo judicial.

Inicialmente, fez-se necessário conhecer a empresa Uber, o modo como ela se apresenta no mercado e o desempenho de suas atividades.

Posteriormente, a decisão judicial passa a ser analisada com a finalidade de compreender os critérios de fundamentação utilizados pelo juiz. O objetivo é conhecer os elementos estruturantes da decisão que possam identificar a metodologia desenvolvida. O conhecimento desses elementos servirá para avaliar se a decisão representa uma forma de ativismo judicial. 
A partir de então, aborda-se a atividade jurisdicional no constitucionalismo contemporâneo para tratar do ativismo judicial como fenômeno em expansão na realidade brasileira. O intuito é determinar concepções necessárias para compreender a forma de prestação da nova jurisdição constitucional e seu papel na garantia e na efetividade dos Direitos Fundamentais.

Por fim, procurou-se avaliar os critérios da decisão confrontando-a com os princípios constitucionais norteadores da atividade jurisdicional, especialmente o devido processo legal. A finalidade é possibilitar a caracterização do ativismo judicial, em que pese a intenção do magistrado em dar efetividade aos direitos sociais constitucionais.

Assim, a pesquisa se desenvolve pelo método dialético, a partir de análise documental da sentença judicial proferida nos autos do processo de $n^{\circ}$ 0011359-34.2016.5.03.0112 da $33^{a}$ vara do trabalho de Belo Horizonte. Para concretização da proposta, a sentença foi então confrontada com os argumentos teóricos encontrados em artigos científicos e doutrinas nacionais e estrangeiras, em especial a doutrina de Friedrich Müller.

Por se tratar de tema que guarda certa novidade e repercussão social e no intuito de ilustrar o tratamento jurídico dado pela empresa em outros países, utilizou-se ainda de matérias veiculadas em jornais eletrônicos estrangeiros, de circulação e acesso disponíveis na internet.

Importa ainda ressaltar que não faz parte dos objetivos deste estudo avaliar a conformação jurídica da decisão com o direito material, pois isso resultaria na própria análise do mérito da causa, bem como de todos os outros atos processuais que antecederam a sentença. Entende-se que a tarefa de questionar a sentença como resultado processual é algo destinado aos interessados do litígio que possuem a capacidade para impugná-la judicialmente, como fizeram mediante a interposição de recurso já apreciado pelo Tribunal Regional do Trabalho da $3^{a}$ Região ${ }^{3}$.

Destaque-se ainda que a empresa Uber vem enfrentando outras demandas judiciais, especialmente relativas à legalidade do serviço prestado, vez que, embora se intitule como empresa de tecnologia, na prática seria prestadora de serviço de transporte de passageiros e concorre, diretamente, com os serviços de taxis licenciados e regularizados na área urbana. Todavia, estes aspectos também não serão abordados porque fogem ao objetivo desta pesquisa, que necessita permanecer centrada na avaliação dos critérios de decisão que resultaram no reconhecimento de relação de emprego, de modo que não serão enfrentados, nesta oportunidade, aspectos acerca da legalidade da atividade ou da natureza do serviço.

3 A $9^{a}$ Turma do TRT da $33^{a}$ Região reformou por unanimidade a decisão do juiz de primeiro grau ao conhecer o Recurso Ordinário, dando provimento parcial ao apelo para declarar a inexistência de relação de emprego. (BRASIL. Tribunal Regional do Trabalho da 3a Região. Acórdão nº 1704111803811100000013742875. Recorrente: Uber do Brasil LTDA. Recorrido: Rodrigo Leonardo Silva Ferreira. Relator: Desembargadora Maria Stela Álvares da Silva Campos. Belo Horizonte, MG, 23 de maio de 2017. Diário Eletrônico da Justiça do Trabalho Nacional: Caderno Judiciário do Tribunal Regional do Trabalho da 3a Região. Publicação Eletrônica, 25 maio 2017. n. 2234/2017, p. 1154. Disponível em: <https://dejt.jt.jus.br/dejt/f/n/diariocon>. Acesso em: 28 jun. 2017) 


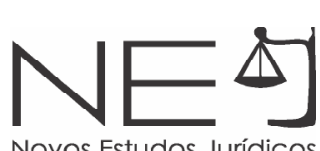

1. A UBER

Com base em São Francisco, na Califórnia, a Uber é uma companhia de rede de transportes internacional criada por Travis Kalanick e Garrett Camp a partir de um aplicativo de celular desenvolvido em 2009. Mediante o uso deste aplicativo, os consumidores poderiam solicitar uma viagem a um motorista privado e a Uber lucraria com $25 \%$ do serviço prestado pelo particular ${ }^{4}$.

A empresa utiliza a tecnologia e-hailing: uma espécie de serviço eletrônico que consiste no ato de solicitar um carro mediante um aplicativo de celular. Por meio deste serviço os motoristas com seus veículos previamente cadastrados transportam os usuários no percurso previamente determinado.

Assim, mediante um aplicativo de celular, a empresa conecta passageiros de um modo conveniente e eficiente, além de proporcionar uma alternativa aos serviços de taxis, porque os carros são solicitados exclusivamente pelo consumidor do serviço, eliminando a necessidade de realizar chamadas por meio de terceiros ${ }^{5}$.

Em seu site ${ }^{6}$, a empresa disponibiliza um guia com informações quanto a diferença existente entre o trabalho de motorista e a atividade de dirigir com a Uber (driving Jobs $X$ driving with Uber), em que enfatiza a diferença entre a oportunidade "ganhar dinheiro" (making money) mediante uma parceria com a empresa ou por meio de uma outra atividade como taxi, motorista de limosine, caminhão ou de entregas. Por meio de uma análise comparativa entre os diferentes tipos de motoristas, a empresa diferencia requisitos, qualificações e remunerações dos trabalhos de motorista e do "uber driver"7.

Por se apresentar como uma empresa de tecnologia, a Uber não teria frota de veículos própria, de modo que não há empregados motoristas por considerar que todos os motoristas cadastrados para prestar serviço mediante o aplicativo seriam trabalhadores autônomos.

4 DEBRUYNE, Nicholas L. Uber Drivers: A disput employment relationship in light of the sharing economy. In: Chicago-Kent Law Review. n. 92. Chicago: 2017, p. 289-316, p. 292.

5 POSEN, Hannah A. Ridesharing in the sharing economy: Should regulators impose über regulations on Uber? In: lowa Law Review. v.101, n. 405. lowa: 2015, p. 405-434. Disponível em: < http://heinonline.org>. Acesso em: 24 de agosto de 2017., p. 415

6 INC., Uber Technologies. Driving jobs vs. Driving with Uber. Disponível em: <https://www.uber.com/driverjobs/>. Acesso em: 23 maio 2017.

7 A opção pela utilização do termo em inglês neste contexto consiste em enfatizar a diferença que empresa realiza em seu site: ter o trabalho de motorista não é ser um motorista uber. Na língua inglesa o driver é aquele que dirige um veículo e deriva do verbo to drive. Assim, o termo não é apenas utilizado no sentido de ser motorista, quando da tradução para o português, mas como o uber driver, algo como um "guiador uber" ou "dirigidor uber". O motorista, na verdade, teria um driver job, enquanto que o uber driver seria qualquer pessoa que guia um veículo mediante a utilização do aplicativo para ganhar dinheiro. Assim a intenção da empresa em passar a ideia de prestador de serviço autônomo fica mais evidente. 


\section{A DECISÃO}

A sentença judicial ${ }^{8}$ sob análise reconheceu a existência de vínculo de emprego entre motorista e a empresa de tecnologia Uber. O reclamante, ex motorista cadastrado no aplicativo, ingressou com a ação alegando dispensa unilateral e abusiva, sem receber verbas trabalhistas. A empresa, por sua vez, alegou ausência dos elementos identificadores da relação de trabalho para fundamentar a inexistência de vínculo empregatício. No entanto, o autor da demanda alegou a existência da relação de emprego e pediu o reconhecimento do vínculo e deferimento de todas as verbas trabalhistas. Argumentou ser comissionista puro e prestador de serviço mediante jornada extraordinária habitual, muitas vezes noturna, mediante a percepção de salário mensal entre $R \$ 4.000,00$ e $R \$ 7.000,00$ mensais.

Antes de analisar o caso, o magistrado tece considerações iniciais para situar o momento contemporâneo de desenvolvimento das relações de trabalho vivenciadas com o avanço da tecnologia. Após abordar o toyotismo e o fordismo, o magistrado conclui que a demanda trata da "uberização das relações de trabalho"

Mediante essas premissas, passa então a analisar o caso concreto pontuando todos os elementos fáticos-jurídicos capazes de determinar a existência de vínculo de emprego para, ao final, reconhecer que o autor desempenhava a função de motorista com pessoalidade, não-eventualidade, onerosidade e subordinação.

Por considerar presentes todos os elementos da relação de emprego, conclui pela condenação da empresa no pagamento de todas as verbas trabalhistas, inclusive horas extras e adicional noturno, bem como o ressarcimento de despesas com combustível, água e balas oferecidas pelo motorista aos usuários do serviço em razão da relação de emprego.

Apenas a título de esclarecimento, visto que não faz parte do objetivo deste trabalho adentrar na análise do mérito da demanda, a sentença foi reformada pela $9^{a}$ Turma do $33^{\circ}$ Tribunal Regional do Trabalho que não identificou a existência de vínculo empregatício ${ }^{10}$.

$8 \quad$ BRASIL. Tribunal Regional do Trabalho da $3^{a}$ Região. Sentença $n^{\circ} 17013114275439000000038127039,33^{a}$ Vara do Trabalho. Autor: Rodrigo Leonardo Silva Ferreira. Réu: Uber do Brasil Tecnologia LTDA. Réu: Uber do Brasil Tecnologia LTDA.. Relator: Juiz Márcio Toledo Gonçalves. Belo Horizonte, MG, 13 de fevereiro de 2017. Diário Eletrônico da Justiça do Trabalho Nacional: Caderno Judiciário do Tribunal Regional do Trabalho da $3^{\text {a }}$ Região. Publicação Eletrônica, 14 fev. 2017. n. 2169/2017, p. 1721-1741. Disponível em: <https://dejt.jt.jus.br/dejt/f/n/ diariocon>. Acesso em: 28 jun. 2017.

9 BRASIL. Diário Eletrônico da Justiça do Trabalho Nacional: Caderno Judiciário do Tribunal Regional do Trabalho da $3^{a}$ Região. Publicação Eletrônica, 14 fev. 2017. n. 2169/2017, 2017, p. 9-10.

10 A $9^{a}$ Turma do Tribunal Regional do Trabalho da $3^{\text {a }}$ Região afastou a tese de existência de subordinação estrutural porque a empresa se caracteriza como plataforma digital e apenas interliga cadastrados aos usuários: "Dissinto do r. entendimento primeiro, uma vez que o objeto social da reclamada refere-se ao fornecimento de serviços de contatos entre pessoas que necessitam de transportes e pessoas que se dispõem a fazer este transporte, que o desenvolvimento da tecnologia possibilitou, e não o transporte de passageiros, devendo ser ratificados os termos dos documentos apresentados nesse sentido [...]" (BRASIL. Diário Eletrônico da Justiça do Trabalho Nacional: Caderno Judiciário do Tribunal Regional do Trabalho da $3^{\text {a }}$ Região, Publicação Eletrônica, 25 maio 2017. n. 2234/2017, 2017, p. 17). 
No contexto fático, o Tribunal entendeu que, quanto aos requisitos da relação de emprego do artigo $3^{\circ}$ da CLT, apenas seria possível identificar a onerosidade, mas a comprovação de apenas um elemento fático não seria suficiente para caracterizar a relação de emprego ${ }^{11}$.

Contudo, no âmbito internacional, a empresa Uber sofreu condenações importantes em demandas judiciais com o mesmo fundamento: reconhecimento de direitos derivados da relação de emprego. Em disputa judicial na Califórnia a Uber foi condenada a indenizar motorista reconhecido como empregado ao se constatar que a empresa se comportava como empregadora em diversas situações. A Uber apelou da decisão, alegando que não tinha controle sobre as horas trabalhadas, vez que se limita a estabelecer a conexão entre passageiros e motoristas autônomos ${ }^{12}$.

Em Londres, a empresa perdeu caso ao sustentar que os motoristas eram autônomos. O Tribunal britânico reconheceu o direito ao salário mínimo, auxílio doença e férias remuneradas. Para o Tribunal do Trabalho de Londres a ideia de que a empresa não presta serviço de transporte é mera ficção com a pretensão de esconder a verdadeira natureza da relação dos motoristas com a empresa ${ }^{13}$.

No entanto, a Uber afirma que seus motoristas são autônomos e independentes, portanto podem escolher quando trabalham. Ademais, a empresa alega que não presta serviço de transporte porque é uma empresa de tecnologia que apenas facilita a conexão entre motoristas autônomos e passageiros que necessitam do serviço.

\subsection{UBERIZAÇÃO DAS RELAÇÕES LABORAIS}

Antes de passar para a análise do caso concreto, o magistrado inovou ao apresentar uma introdução sobre os sistemas produtivos contemporâneos, por entender que, apesar da demanda ser individual, teria potencial metaindividual ${ }^{14}$.

11 BRASIL. Diário Eletrônico da Justiça do Trabalho Nacional: Caderno Judiciário do Tribunal Regional do Trabalho da 3a Região, Publicação Eletrônica, 25 maio 2017. n. 2234/2017, 2017, p. 19.

12 ISAAC, Mike; SINGER, Natasha. California says Uber driver is employee, not a contractor. The New York Times, New York, 17/06/2015, Technology. Disponível em: https://www.nytimes.com/2015/06/18/business/uber-contestscalifornia-labor-ruling-that-says-drivers-should-be-employees.html. Acesso em: 23 de maio de 2017.

13 OSBORNE, Hilary. Uber loses right to classify UK drivers as self-employed. The Guardian, London, 28/10/2016, Technology. Disponível em: <https://www.theguardian.com/technology/2016/oct/28/uber-uk-tribunal-selfemployed-status>. Acesso em: 23 de maio de 2017.

14 A $9^{a}$ Turma do Tribunal Regional do Trabalho da $3^{a}$ Região asseverou que, por se tratar de um caso específico, seri fundamental se ater exclusivamente às provas produzidas em razão de peculiaridades que não poderiam ser afastadas. Assim, acatou o argumento da empresa, pois a contextualização introdutória realizada pelo magistrado o levaram a julgar, em verdade, uma Ação Civil Pública que sequer fora proposta contra a empresa, especialmente quando se justifica o desenvolvimento histórico do tema em razão da potencial natureza meta individual da demanda. (BRASIL. Diário Eletrônico da Justiça do Trabalho Nacional: Caderno Judiciário do Tribunal Regional do Trabalho da $3^{\text {a }}$ Região, Publicação Eletrônica, 25 maio 2017. n. 2234/2017, 2017, p. 14). 
Após realizar uma contextualização histórica do fenômeno que envolve a relação capitaltrabalho, abordando o fordismo e o toyotismo, o magistrado concluiu que a sociedade urbana industrial está diante de um novo modelo de organização do trabalho: a "uberização"15.

Assim, entendeu que a empresa Ré empresta seu nome ao fenômeno "porque é o arquétipo desse atual modelo, firmado na tentativa de autonomização dos contratos de trabalho e na utilização de inovações disruptivas nas formas de produção."16

Portanto, trata-se de um novo padrão de organização de trabalho a partir do avanço da tecnologia. Ainda nas palavras do magistrado:

Qualquer processo econômico que possua, em sua essência material, extração e apropriação do labor que produz mercadorias e serviços atrairá a aplicação deste conjunto normativo, sob o risco de, em não fazendo, precipitar-se em retrocesso civilizatório ${ }^{17}$.

Tais considerações iniciais servirão de premissa para a identificação dos elementos fáticosjurídicos caracterizadores da relação de emprego reconhecida no caso concreto. Conforme será abordado mais adiante, é nesse momento que o magistrado inicia uma estruturação argumentativa que o levará ao reconhecimento da relação de emprego.

\subsection{OS ELEMENTOS DA RELAÇÃO DE EMPREGO}

Quanto ao enquadramento jurídico, o magistrado reconhece a necessidade de observância do princípio da primazia da realidade e passa a analisar os elementos fáticos-jurídicos que caracterizam a relação de emprego.

A partir do artigo $3^{\circ}$ da Consolidação das Leis do Trabalho, a doutrina construiu elementos que, identificados na realidade fática, caracterizam uma relação de emprego. Assim, uma vez caracterizada no caso concreto a pessoalidade, a não eventualidade, a onerosidade e a subordinação na prestação de serviços por pessoa física, se terá, na prática, uma relação de emprego.

O magistrado analisou pontualmente cada um desses elementos e destacou os motivos pelos quais todos estariam presentes no caso. Observe-se que não se insere no objeto do presente estudo a conferência da identificação da relação de emprego, vez que não se confrontará as provas produzidas com os argumentos apresentados.

15 BRASIL. Diário Eletrônico da Justiça do Trabalho Nacional: Caderno Judiciário do Tribunal Regional do Trabalho da $3^{\text {a }}$ Região. Publicação Eletrônica, 14 fev. 2017. n. 2169/2017, 2017, p. 10.

16 BRASIL. Diário Eletrônico da Justiça do Trabalho Nacional: Caderno Judiciário do Tribunal Regional do Trabalho da $3^{\text {a }}$ Região. Publicação Eletrônica, 14 fev. 2017. n. 2169/2017, 2017, p. 10.

17 BRASIL. Diário Eletrônico da Justiça do Trabalho Nacional: Caderno Judiciário do Tribunal Regional do Trabalho da $3^{\text {a }}$ Região. Publicação Eletrônica, 14 fev. 2017. n. 2169/2017, 2017, p. 11. 
A exposição da argumentação do juiz em cada um desses elementos apenas se faz com a finalidade ilustrativa da metodologia utilizada. Mais adiante, se demonstrará que a premissa da "uberização" foi responsável pela caracterização da relação de emprego, pois qualquer que fossem os elementos fáticos elencados pela lei o magistrado encontraria argumentos para identificá-los no caso concreto.

\subsubsection{A PESSOALIDADE}

Sabe-se que o motorista Uber é pessoa física que desempenha suas funções em razão da existência de um cadastro prévio que o identifica com um perfil no aplicativo do celular.

Neste aspecto, o magistrado se apoia em depoimento de testemunha para identificar a pessoalidade em razão da existência de cadastro prévio necessário para desempenhar a atividade de motorista. Ademais, a prova testemunhal revelou que outros documentos pessoais também seriam necessários para exercer a função, razão pela qual reconheceu o caráter intuito personae da relação jurídica, especialmente diante da revelação de que não é permitido ao motorista ceder sua conta no aplicativo a outra pessoa cadastrada ${ }^{18}$.

O juiz ainda destaca que o fato de haver possibilidade de compartilhamento de veículos cadastrados entre os motoristas não torna a relação fungível ${ }^{19}$, pois o automóvel seria mera ferramenta de trabalho e não tem relação de dependência com os elementos fáticos-jurídicos do vínculo de emprego.

2.2.2. ONEROSIDADE

Na identificação da existência de contraprestação econômica pelo trabalho desempenhado, o magistrado entendeu revelado que era a empresa que realizava a política de pagamento pelo serviço prestado, pois conduzia de forma exclusiva a forma de pagamento e a oferta de promoções e descontos ${ }^{20}$. Com base nos depoimentos das testemunhas, identificou-se a inexistência de gerência do próprio negócio, pois o motorista ainda recebia prêmios pelo alcance de certas condições previamente estabelecidas pela empresa, bem como era remunerado ainda que a viagem fosse gratuita ao usuário.

Ademais, as provas documentais teriam comprovado que a empresa na verdade recebe pelo serviço prestado pelos seus motoristas e não apenas intermedia negócios, vez que apenas repassa os pagamentos realizados pelos usuários ao final de cada semana, após retirar seu percentual. Deste

18 BRASIL. Diário Eletrônico da Justiça do Trabalho Nacional: Caderno Judiciário do Tribunal Regional do Trabalho da $3^{\text {a }}$ Região. Publicação Eletrônica, 14 fev. 2017. n. 2169/2017, 2017, p. 12.

19 BRASIL. Diário Eletrônico da Justiça do Trabalho Nacional: Caderno Judiciário do Tribunal Regional do Trabalho da $3^{a}$ Região. Publicação Eletrônica, 14 fev. 2017. n. 2169/2017, 2017, p. 13.

20 BRASIL. Diário Eletrônico da Justiça do Trabalho Nacional: Caderno Judiciário do Tribunal Regional do Trabalho da $3^{a}$ Região. Publicação Eletrônica, 14 fev. 2017. n. 2169/2017, 2017, p. 15. 
modo, o magistrado entendeu que a empresa recebe diretamente pelo serviço e após remunera o motorista, seu trabalhador.

\subsubsection{NÃO-EVENTUALIDADE}

Para a configuração da não-eventualidade o juiz se fundamenta na teoria dos fins do empreendimento combinada com a teoria da eventualidade ${ }^{21}$. Assim, compreende que a condição de motorista da empresa Uber não configura trabalho eventual, já que a eventualidade caracteriza o desempenho de uma atividade em razão de um acontecimento ou evento específico capaz de resultar em um serviço de duração transitória.

Para o magistrado 22 , tal transitoriedade não fica configurada porque os motoristas cadastrados atendem à demanda intermitente, comprovadas, inclusive, mediante os demonstrativos de pagamento juntados aos autos. Ademais, o conjunto probatório teria demonstrado exigência velada para que os motoristas estivessem em atividade de forma sistêmica.

Já no contexto da teoria dos fins do empreendimento, o magistrado a combina com o princípio da primazia da realidade para afastar a finalidade declarada pela empresa ${ }^{23}$. Neste aspecto, não se trataria de uma empresa de tecnologia, mas de uma moderna empresa de transporte de passageiros, de modo que o trabalho do motorista é não eventual, pois desenvolve atividades para os fins normais da empresa.

\subsubsection{SUBORDINAÇÃO}

Ao proceder a análise da relação para a identificação da subordinação o magistrado considera a dificuldade de identificação deste elemento em razão das mudanças ocorridas no mundo do trabalho. No entanto, identifica a subordinação em suas diversas formas ${ }^{24}$, pois na hipótese dos autos o autor estava submisso a ordens sobre o modo de desenvolver a prestação do serviço: treinamento de pessoal, código de conduta, regras e padrões de atendimento, controle automatizado por meio de algoritmos, sujeição a um sistema de avaliação contínuo pelos consumidores do serviço, além da inserção do trabalhador na estrutura do empreendimento.

Para o magistrado 25 , a exteriorização dos comandos diretos para fins de caracterização da subordinação não seria o mais importante, pois, em essência, o que vale mesmo é a inserção objetiva do trabalhador no núcleo da atividade empresarial. Assim, concluiu que, a empresa elaborou um

21 BRASIL. Diário Eletrônico da Justiça do Trabalho Nacional: Caderno Judiciário do Tribunal Regional do Trabalho da $3^{a}$ Região. Publicação Eletrônica, 14 fev. 2017. n. 2169/2017, 2017, p. 17.

22 BRASIL. Diário Eletrônico da Justiça do Trabalho Nacional: Caderno Judiciário do Tribunal Regional do Trabalho da $3^{a}$ Região. Publicação Eletrônica, 14 fev. 2017. n. 2169/2017, 2017, p. 17.

23 BRASIL. Diário Eletrônico da Justiça do Trabalho Nacional: Caderno Judiciário do Tribunal Regional do Trabalho da $3^{\text {a }}$ Região. Publicação Eletrônica, 14 fev. 2017. n. 2169/2017, 2017, p. 18.

24 BRASIL. Diário Eletrônico da Justiça do Trabalho Nacional: Caderno Judiciário do Tribunal Regional do Trabalho da $3^{a}$ Região. Publicação Eletrônica, 14 fev. 2017. n. 2169/2017, 2017, p. 22-27.

25 BRASIL. Diário Eletrônico da Justiça do Trabalho Nacional: Caderno Judiciário do Tribunal Regional do Trabalho da $3^{\text {a }}$ Região. Publicação Eletrônica, 14 fev. 2017. n. 2169/2017, 2017, p. 25. 
método fragmentado de exploração de mão-de-obra na tentativa de se esquivar da legislação trabalhista, de modo a não identificar os profissionais contratados como seus empregados.

\section{A MUDANÇA PARADIGMÁTICA DO DIREITO NO CONSTITUCIONALISMO CONTEMPORÂNEO}

A decisão ora estudada representa a dificuldade prática enfrentada pela jurisdição contemporânea. Diante do avanço tecnológico a resposta legislativa não acompanha as necessidades sociais, sobretudo as novas relações derivadas do avanço da internet e da velocidade das informações.

Conforme visto, essa dificuldade parece não surgir apenas no Brasil, mas em outros lugares do mundo, de modo que o aplicador do direito se vê forçado a adaptar as novas situações fáticas à antigas molduras jurídicas, na pretensão de sua eficiência mediante a preservação da segurança.

Nos últimos anos, um novo ideal composto de valores, princípios e novas técnicas de hermenêutica vem sendo identificado pela doutrina como pós-positivismo, uma designação provisória para a mudança percebida na Teoria do Direito que valoriza princípios e reaproxima o Direito com a Moral ${ }^{26}$.

Esta nova Teoria do Direito estaria relacionada com a modificação do constitucionalismo da pós-modernidade, proporcionado pela abertura do sistema constitucional com fundamento na dignidade da pessoa humana ${ }^{27}$, mas ainda não há consenso quanto à correta designação aplicável ao fenômeno decorrente dessa nova visão.

Trata-se, portanto, de um paradigma diferenciado, capaz de carregar consigo uma série de características como, por exemplo, o pragmatismo, ojudicialismo ético-jurídico, o juízo de ponderação e a adoção de um conceito não positivista do direito ${ }^{28}$.

É neste cenário que a decisão ora em estudo foi concebida. Os ideais trazidos pelo "neoconstitucionalismo" representou o fim dos modelos desconectados com o compromisso de concretização constitucional, de modo que se evidenciou uma incompatibilidade com o modelo positivista ${ }^{29}$.

26 BARROSO; BARCELLOS, Ana Paula. O começo da história: a nova interpretação constitucional e o papel dos princípios no Direito Brasileiro. In: Revista latino-americana de estudos constitucionais. n. 2. Belo Horizonte: Del Rey, 2003. jul-dez. p. 175-210, p. 175.

27 CASTRO, Carlos Roberto Siqueira. A Constituição aberta e os Direitos Fundamentais. Rio de Janeiro: Forense, 2005, p. 19.

28 DUARTE, Écio Oto Ramos; POZZOLO, Susanna. Neoconstitucionalismo e Positivismo Jurídico: as faces da Teoria do Direito em tempos de interpretação moral da Constituição. São Paulo: Landy Editora, 2010, p. 64-65.

29 AGRA, Walber de Moura. Neoconstitucionalismo e superação do positivismo. Direitos Humanos Fundamentais e as Constituições brasileiras. In: Constitucionalismo social: estudos em homenagem ao Ministro Marco Aurélio de Farias Mello, São Paulo: Editora LTR, 2003, p. 437. 
No entanto, uma nova teoria da Constituição não pode se centrar unicamente na ultrapassagem do positivismo como ciência jurídica, pois, no desenvolvimento de uma teoria democrática da Constituição, é importante observar o discurso sobre o método, consistente na revelação de uma dogmática jurídica adequada ao modelo30.

Esta constatação assume fundamental importância no desenvolvimento da ideia deste estudo, conforme será tratado mais adiante.

\section{A ATIVIDADE JURISDICIONAL NO ESTADO CONSTITUCIONAL BRASILEIRO: O ATIVISMO JUDICIAL}

No tópico anterior, esclareceu-se que o cenário jurídico da contemporaneidade é orientado pela ideia de abertura do sistema constitucional para permitir a concretização da Constituição, sobretudo do princípio da dignidade da pessoa humana.

Desse modo, a atividade jurisdicional passou a receber as orientações "neoconstitucionais"31. Impõe-se que na interpretação das normas jurídicas, o julgador busque a máxima efetividade constitucional, exigindo-se, por vezes, a utilização de princípios capazes de concretizar os valores constitucionais quando aplicados ao caso concreto. Nesse aspecto, Lenio Streck alerta que "centenas de princípios invadiram o universo da interpretação e aplicação do direito, fragilizando sobremodo o grau de autonomia do direito e a própria força normativa da Constituição"32. Identifica-se, assim, a preponderância da função ativa do juiz na solução do caso concreto a partir de princípios para privilegiar-se o senso de justiça percebido pelo juiz.

Por se tratar de um fenômeno recente, ainda não se sabe ao certo as reais transformações que esta mudança paradigmática acarretará na teoria do direito, mas já é possível identificar algumas consequências na prática jurídica contemporânea, especialmente na metodologia jurídica para a construção da decisão.

A doutrina nacional reagiu criticamente e passou a chamar de ativismo judicial esta performance do Poder Judiciário consistente em concretizar, a qualquer custo, os valores constitucionais. Ao identificar princípios e regras abertas como casos centrais da prática jurídica, o

30 DUARTE, Écio Oto Ramos; POZZOLO, Susanna. Neoconstitucionalismo e Positivismo Jurídico: as faces da Teoria do Direito em tempos de interpretação moral da Constituição, 2010, p. 61.

31 A opção pela utilização da expressão entre aspas se deve ao fato de que ainda não há um consenso sobre a utilização da terminologia adequada para os fenômenos vivenciados pelo constitucionalismo contemporâneo. Segundo Suzana Pozzolo - Neoconstitucionalismo éum termo bem apropriado. Originalmente pensado para denominar um certo modo antijuspositivista de se aproximar do direito, talvez também devido a uma certa indeterminação ou vagueza que Ihe foram atribuídaspor usos um pouco diversos, já que o termo enfrentou uma rápida e ampla difusão no léxico dos jusfilósofos, sobretudo em língua italiana e espanhola. $\square$. (DUARTE, Écio Oto Ramos; POZZOLO, Susanna. Neoconstitucionalismo e Positivismo Jurídico: as faces da Teoria do Direito em tempos de interpretação moral da Constituição, 2010, p. 78).

32 STRECK, Lenio Luiz. Jurisdição constitucional e decisão jurídica. 4. ed. São Paulo: Editora Revista dos Tribunais, 2014, p. 301. 
"neoconstitucionalismo" opta pela dimensão da justificação, adotando-se um modelo voltado para a substância das decisões, de maneira a privilegiar a via judicial, minimizando-se os procedimentos políticos de tomada de decisão ${ }^{33}$.

A crítica se sustenta no fato de que o Estado Democrático de Direito brasileiro tem a pretensão de proporcionar um registro político para abranger o máximo de democracia e de Estado de Direito. Desse modo, na medida que a Constituição agrega princípios e preceitos fundamentais, mais relevante se torna o papel da justiça constitucional e dos órgãos do Poder Judiciário. Porém, a preocupação da metodologia contemporânea está no excesso do Poder Judiciário na atividade de interpretação das normas constitucionais ${ }^{34}$. Streck ${ }^{35}$ explica que o ativismo judicial faz parte de um gênero maior, o protagonismo judicial. Este pode causar prejuízos para a democracia, porque pode nulificar ou embargar uma série de opções realizadas pelo legislador e faz surgir uma tendência de utilização política do Poder Judiciário. No ativismo, como uma das modalidades de protagonismo judicial, a promoção dos fins sociais é entregue à atividade jurisdicional.

Portanto, o problema parece ser quanto ao modo de atuação do juiz que, mediante a utilização do seu poder discricionário, atua de modo não vinculado e sem a devida análise das circunstâncias do caso concreto, mediante justificação genérica nos princípios constitucionais.

Para Mauro Cappellettij ${ }^{36}$, as Constituições modernas não se limitam a dizer estaticamente o que é o direito, mas estabelecem um programa de reformas em direção ao futuro. Assim, a atividade de interpretação do juiz para fazer atuar a norma constitucional é acentuadamente discricionária. Mas esta discricionariedade deve considerar os limites que todo poder encontra no Estado Constitucional, dada a intrínseca característica de poder por derivação, portanto naturalmente limitado.

Desse modo, os espaços livres de apreciação são diferentes de genuínas atribuições de poder discricionário, pois não há liberdade de decisão segundo concepções próprias. Para Engisch ${ }^{37}$, o autêntico poder discricionário é atribuído pelo direito e pela lei quando se confia a alguém a responsabilidade sobre o justo no caso concreto. É, portanto, uma discricionariedade vinculada, porque o exercício deste poder deve ser endereçado a uma finalidade e a um resultado da decisão, depois de realizadas as considerações sobre as circunstâncias do caso concreto.

Assim, este novo paradigma não possibilita uma atuação estatal sem critérios e nem possibilita o desprezo pelo ordenamento jurídico infraconstitucional. Esses são sintomas da utilização equivocada ou da incompreensão desta renovação proporcionada pelo constitucionalismo contemporâneo.

33 GALVÃO, Jorge Octávio Lavocat. O neoconstitucionalismo e o fim do Estado de Direito, 2014, p. 168.

34 STRECK, Lenio Luiz. Jurisdição constitucional e decisão jurídica, 2014, p. 44-45.

35 STRECK, Lenio Luiz. Jurisdição constitucional e decisão jurídica, 2014, p. 47.

36 CAPPELLETTI, Mauro. O Controle judicial de constitucionalidade das leis no direito comparado. Tradução. Aroldo Plínio Gonçalves. 2. ed. Porto Alegre: Sergio Antonio Fabris Editor, 1992, p. 89. 


\section{OS LIMITES DA ATIVIDADE JURISDICIONAL}

As mudanças proporcionadas pelo constitucionalismo contemporâneo na Teoria do Direito também influenciam e direcionam a nova Teoria do Processo, conforme se observa na redação do artigo $1^{\circ}$ do novo Código de Processo Civil ${ }^{38}$. Contudo, antes mesmo da mudança legislativa, a ciência processual já indicava a necessidade de ajuste da prática jurídica tradicional aos objetivos constitucionais. Cândido Rangel Dinamarco, ${ }^{39}$ ao estruturar a sua teoria da instrumentalidade do processo, compreendeu o processo como instrumento de mutações na ordem constitucional e legal. O juiz, ao exercer o poder nacional em nome do Estado, realiza a interpretação para ditar decisões capazes de influir no Conteúdo das Constituições, das leis e dos significados de seus textos, "mas isso não significa que a função jurisdicional seja constitutiva de direitos, nem que a jurisprudência seja fonte normativa"40.

Do ponto de vista político, a jurisdição é poder entregue ao Estado por meio de autorização constitucional. Compreende-se que a escolha do sistema político foi eleger órgãos estatais com a função de realizar a atividade de resolução de conflitos e concretização de direitos. Daí deriva a necessidade de estabelecer limites, sob pena de arbitrariedade e abuso do poder, características eliminadas com a instituição do Estado Democrático de Direito.

Para Dinamarco ${ }^{41}$, o processo é um meio para a obtenção de fins múltiplos e há finalidades que precisam ser observadas no plano político, jurídico e social. No aspecto político, enfatiza que há uma necessidade de manter um equilíbrio entre a liberdade dos indivíduos e o poder estatal, de modo que se torna essencial limitar os contornos e o exercício deste poder ${ }^{42}$.

Na Teoria do Direito, a interpretação e a aplicação da norma jurídica também é estudada sob o enfoque do constitucionalismo contemporâneo. A concretização dos Direitos Fundamentais mediante uma metódica estruturante é a solução encontrada por Friedrich Müller ${ }^{43}$ como a mais adequada para a concepção de teoria pós-positivista do Direito.

38 "Art. 10 O processo civil será ordenado, disciplinado e interpretado conforme os valores e as normas fundamentais estabelecidos na Constituição da República Federativa do Brasil, observando-se as disposições deste Código.". (BRASIL. Lei n 13.105, de 16 de março de 2015. Código de Processo Civil. Brasília, DF).

39 DINAMARCO, Cândido Rangel. A instrumentalidade do processo. 12. ed. São Paulo: Malheiros editores, 2005, p. 45.

40 DINAMARCO, Cândido Rangel. A instrumentalidade do processo. 12. ed. São Paulo: Malheiros editores, 2005, p. 47.

41 DINAMARCO, Cândido Rangel. A instrumentalidade do processo. 12. ed. São Paulo: Malheiros editores, 2005, p. 188.

42 DINAMARCO, Cândido Rangel. A instrumentalidade do processo. 12. ed. São Paulo: Malheiros editores, 2005, p. 205.

43 MÜLLER, Friedrich. O novo paradigma do Direito: Introdução à teoria e metódica estruturantes. 2. ed. revista, ampliada, atualizada. São Paulo: Revista dos Tribunais, 2009, p. 11. 
Para Müller, a norma é criada no caso, mas está estruturada a partir de um programa, consistente no texto codificado que funciona como um dado de entrada para a concretização ${ }^{44}$. Sua proposta baseia-se no método indutivo, porque a teoria do Direito se torna realista e não é absorvida pela pretensão normativa do Direito e desenvolve seus esquemas conceituais de forma intrajurídica, sem dedução filosófica ${ }^{45}$.

\subsection{INSTRUMENTALIDADE E MÉTODO}

Interessante notar que Dinamarco, ao tratar da teoria geral do processo também conclui pelo método indutivo para chegar à instrumentalidade como "nota central do sistema e tendência metodológica do direito processual contemporâneo como um todo." ${ }^{46}$. Observa ainda que a visão metodológica unitária de direito processual não significa uma homogeneidade de soluções.

Portanto, apesar de toda a abstração que envolve o conhecimento do Direito no paradigma pós-positivista, a observância de um método capaz de estruturar o processo interpretativo será indispensável. Isso se deve ao fato de que a limitação do poder nas relações de sujeição constitui máxima democrática do Estado de Direito ${ }^{47}$.

É por esse aspecto que se enfatiza a interpretação das normas jurídicas para a construção de uma decisão como resultado do desempenho de uma função estatal derivada de uma outorga democrática de poder. Na visão da teoria do processo pautada na instrumentalidade, o processo possui um significado político, mas a fixação de valores para a concretização depende dos parâmetros indicados na norma jurídica.

Ao explicar a íntima relação entre direito e política, Müller esclarece que deve haver distinção entre as influências políticas e a utilização das normas jurídicas no processo decisório, pois cumpre ao legislador realizar esforços para constituir normas mais precisas possíveis no Estado de Direito:

Tendências' não são leis; entretanto, constatam-se esforços políticosconstitucionais e, em parte, também práticas administrativas, os quais apontam a uma generalização dificilmente assimilável pelo Estado de Direito. ${ }^{48}$

44 Neste aspecto, Müller se diferencia de Dinamarco, porque este último é adepto do dualismo jurídico, por acreditar que o direito substancial não é dependente do direito processual e este não é capaz de criar situações jurídicas. (DINAMARCO, Cândido Rangel. A instrumentalidade do processo, 2005, p. 255). Já Müller acredita que a decisão representa uma co-constituição da norma que não existiria antes do caso. Para o ele, $\square$ todos esses dualismos são representações centrais fracassadas do positivismo histórico. $\square$ (MÜLLER, Friedrich. 0 novo paradigma do Direito, 2009, p. 11.).

45 MÜLLER, Friedrich. O novo paradigma do Direito, 2009, p. 12.

46 DINAMARCO, Cândido Rangel. A instrumentalidade do processo, 2005, p. 89.

47 DINAMARCO, Cândido Rangel. A instrumentalidade do processo, 2005, p. 90.

48 MÜLLER, Friedrich. Metódica Jurídica e Sistema Político: Elementos de Teoria Constitucional II, 2014, p. 98. 
Por essa afirmação, é perceptível que não se deve desprezar as tendências sociais ou as influências políticas que margeiam a decisão. Mas a ideia de poder aproxima o processo da política, porque as escolhas axiológicas e a fixação dos destinos do Estado fazem parte de uma decisão que deve ser tomada por meios públicos ${ }^{49}$. Desta forma, o juiz se torna um modelador da vida social, conforme aduz Engisch ${ }^{50}$, porque não deve ser apenas um súdito do legislador, mas pode contribuir na direção das correntes do seu tempo, sem ir além daquilo que constitui a arte específica do pensamento do jurista.

Para Dworkin ${ }^{51}$, a tarefa de interpretar é holística porque o intérprete busca integrar um plano de fundo de valores e intuições interpretativas concretas. Contudo, a estrutura permanecesse sendo importante porque permite o foco nas conexões cruciais entre valores e padrões interpretativos.

Assim, é compreensível que o juiz ao interpretar, contribua de alguma forma na completude do texto da lei, afinal é um intérprete legitimado para a busca dos significados trazidos pelo caso concreto. Mas é necessário impedir que esses significados encontrados pelo juiz se desvirtuem do caminho traçado pelo Estado de Direito.

\subsection{SISTEMA PROCESSUAL E DEVIDO PROCESSO LEGAL}

No Brasil, a Constituição de 1988 conferiu destaque aos direitos sociais quando estabeleceu uma série de normas e princípios constitucionais a partir do seu artigo $6^{\circ}$, inaugurando um capítulo exclusivo do texto a respeito dos Direitos Sociais inserido no título de Direitos e Garantias Fundamentais. A existência de uma organização de regras e princípios no texto constitucional caracteriza o Estado de Direito brasileiro e serve de substância para o desenvolvimento do ordenamento jurídico infraconstitucional.

Conforme aduz Canotilho ${ }^{52}$ a juridicidade do Estado de Direito é proporcionada pela ideia de um princípio constitutivo de natureza formal, material e procedimental que confere a "medida do direito", de modo que a ordenação racional da sociedade se estabelece por meio de regras e medidas que prescrevem formas, procedimentos e cria instituições.

Para possibilitar o desempenho da atividade jurisdicional pelo Estado, o sistema jurídico edificou normas capazes de conferir concretização aos princípios constitucionais de acesso à justiça e inafastabilidade do Poder Jurisdicional. Deste modo, o Direito Processual surge como ramo do direito público responsável pela disciplina da jurisdição e do direito de ação, estabelecendo-se o processo como instrumento de obtenção da tutela jurisdicional.

49 DINAMARCO, Cândido Rangel. A instrumentalidade do processo, 2005, p. 100.

50 ENGISCH, Karl. Introdução ao pensamento jurídico, 2008, p. 255.

51 DWORKIN, Ronald. Justice for hedgehogs. Estados Unidos da América: The Belknap Press of Harvard University, 2013, p. 134-135.

52 CANOTILHO, José Joaquim Gomes. Direito Constitucional e teoria da constituição. 7. ed. 4. reimpr. Coimbra: editora Almedina, 2003, p. 243. 
O desenvolvimento do processo como ciência proporcionou a autonomia necessária para a construção de conceitos e ideias comuns em qualquer sistema processual. As grandes premissas metodológicas foram desenvolvidas e toda a estrutura sistemática foi traçada, de modo que hoje é possível identificar no direito processual o sentido de assegurar o juiz natural e o devido processo legal mediante a participação equilibrada de seus interessados ${ }^{53}$.

Mas foi por meio do instrumentalismo que a ciência processual se desenvolveu em direção à efetividade. A preocupação do sistema processual com o valor da justiça permite compreender o processo mediante a observância necessária de valores protegidos pela Constituição.

Desta forma, o juiz confere significado aos valores constitucionais mediante a sua atuação como parte do poder estatal e a estrutura traçada pelo estado para a realização desta tarefa é essencial para amparar o juiz no processo interpretativo.

Para Owen Fiss ${ }^{54}$, essa concepção de função judicial em que os juízes tentam dar significado aos valores constitucionais talvez seja demais para os juízes. A obrigação de justificar suas decisões deu ensejo a debates intermináveis quanto à fonte de justificação destas decisões, mas a noção de justificação enseja o suporte da decisão em critérios racionais e se opõe à ideia de mera explicação.

Portanto, a tutela constitucional do processo tem escopo de assegurar o funcionamento dos institutos do direito processual aos princípios que transcendem da própria ordem constitucional ${ }^{55}$. Na ciência processual, o devido processo legal é considerado um supra princípio, pois derivam dele todos os outros princípios orientadores da dinâmica processual no desempenho da jurisdição.

\section{ANÁLISE CRÍTICA DA DECISÃO}

Partindo-se da premissa de que a empresa reclamada é um arquétipo de um modelo firmado na tentativa de autonomização dos contratos de trabalho, o magistrado interrompe a lógica processual para trazer elementos fáticos sociais externos à causa como protagonistas na direção da sua decisão.

Conforme visto, a construção da decisão jurídica nos moldes do constitucionalismo contemporâneo requer a observância de um percurso metodológico capaz de concretizar não apenas os Direitos Fundamentais, mas também as normas processuais para possibilitar a atuação do Estado de modo democrático e justo. Esta é a ideia que se infere da orientação da instrumentalidade, na Teoria Geral do Processo, e da metódica estruturante da Teoria do Direito.

53 DINAMARCO, Cândido Rangel. A instrumentalidade do processo, 2005, p. 22.

54 FISS, Owen. The law as it could be. Estados Unidos da America: New York Universty Press, 2003, p. 11.

55 DINAMARCO, Cândido Rangel. A instrumentalidade do processo, 2005, p. 23. 
Na dinâmica processual a construção da decisão jurídica deve ser desempenhada por meio da interpretação, de modo que as deduções jurídicas derivam de um processo lógico capaz de fornecer ao jurista o conteúdo e o alcance dos conceitos jurídicos.

Ainda que essa a interpretação possa ser exercida a partir de vários pontos de vista, é por meio de uma construção lógica, apoiada na localização de preceitos no texto da lei e mediante fundamentação racional que a hermenêutica jurídica se desenvolve. Porém, este preceito lei deve ser interpretado de modo a ajustar-se o mais possível às exigências da vida em sociedade, vez que o direito é apenas uma parte da cultura global ${ }^{56}$.

No caso em análise, o juiz compreende que as exigências sociais implicam a identificação de um novo padrão de relações de trabalho derivado da tecnologia. Antes mesmo da verificação probatória o juiz estabeleceu um ponto de partida fundamental para construção do seu raciocínio: a "uberização" das relações de trabalho.

Deste modo, não se despreza o valor do resultado, no caso, a concretização de Direito Fundamental relacionado à proteção constitucional do trabalho. Mas a adoção de uma finalidade abstrata não comporta a capacidade argumentativa necessária para sustentar a decisão do ponto de vista jurídico. A ideia de que o sistema processual adota a livre persuasão racional é ultrapassada, sobretudo após as mudanças do novo Código de Processo Civil. A liberdade decisória do juiz é limitada tanto pelas normas processuais, que estabelecem a necessidade de motivação das decisões judiciais ${ }^{57}$, como também pelo sistema democrático republicano que limita constitucionalmente a atuação dos poderes constituídos. Conforme explica Fiss ${ }^{58}$, a escolha do juiz é constrita por uma série de normas e a aderência a estas normas representa a medida de impessoalidade do julgamento.

Desse modo, permanece a necessidade de observância pelo juiz do conteúdo normativo da legislação trabalhista, visto que a comprovação de elementos fáticos resultará no processo interpretativo de adequação do fato ao preceito normativo. Neste aspecto, o juiz realiza o enquadramento jurídico e afirma ser importante configurar a relação de emprego a partir do artigo

56 ENGISCH, Karl. Introdução ao pensamento jurídico, 2008, p. 137-138.

57 Conforme os parágrafos do artigo 489 do Código de Processo Civil, Lei n. ${ }^{\circ} 13.105$ de 16 de março de 2015 : $\S$ $1^{\circ}$ Não se considera fundamentada qualquer decisão judicial, seja ela interlocutória, sentença ou acórdão, que: I - se limitar à indicação, à reprodução ou à paráfrase de ato normativo, sem explicar sua relação com a causa ou a questão decidida; II - empregar conceitos jurídicos indeterminados, sem explicar o motivo concreto de sua incidência no caso; III - invocar motivos que se prestariam a justificar qualquer outra decisão; IV - não enfrentar todos os argumentos deduzidos no processo capazes de, em tese, infirmar a conclusão adotada pelo julgador; $\mathrm{V}$ - se limitar a invocar precedente ou enunciado de súmula, sem identificar seus fundamentos determinantes nem demonstrar que o caso sob julgamento se ajusta àqueles fundamentos; VI - deixar de seguir enunciado de súmula, jurisprudência ou precedente invocado pela parte, sem demonstrar a existência de distinção no caso em julgamento ou a superação do entendimento. $\S 2^{\circ}$ No caso de colisão entre normas, o juiz deve justificar o objeto e os critérios gerais da ponderação efetuada, enunciando as razões que autorizam a interferência na norma afastada e as premissas fáticas que fundamentam a conclusão. $\S 3^{\circ} \mathrm{A}$ decisão judicial deve ser interpretada a partir da conjugação de todos os seus elementos e em conformidade com o princípio da boa-fé. 
$3^{\circ}$ da CLT. Ocorre que, mediante uma "introdução de modo a situar a questão debatida"59, o julgador afasta-se da identificação dos elementos fáticos caracterizadores da relação de emprego para agregar à sua decisão concepções sociológicas e filosóficas. Tais concepções são relevantes para o debate do assunto no contexto acadêmico, mas revelam-se inadequadas para a argumentação jurídica.

Segundo Müller ${ }^{60}$, sempre que a prática jurídica tiver a pretensão de generalizar uma norma diante da versatilidade dos casos concretos, a força determinante da metódica jurídica racional se esmaece porque as opiniões dos que decidem se tornam dominantes a partir de operações de formalização que direcionam o conteúdo.

O fato é que, mediante o argumento da concretização de direitos fundamentais, o foco passa a ser o resultado da decisão, de modo a conferir uma função objetiva ao direito fundamental desenvolvida por antecipação. Neste aspecto, Müller explica que essa função objetiva pertence a um elemento de concretização sem referência normativa e apenas possuem utilidade políticoconstitucional. Portanto, devem ser limitadas a um papel secundário diante da norma, porque representam uma mera variante político-constitucional entre as possibilidades de entendimento do direito fundamental à liberdade científica ${ }^{61}$.

Alexy ${ }^{62}$ observa que uma das maiores diferenças entre a argumentação jurídica e a argumentação prática geral é que as disputas jurídicas não submetem todas as questões da discussão e, no caso do processo, estão limitadas por regras processuais que regulam o processo de argumentação.

A ideia prévia de que a relação de emprego é configurada como um exemplo da chamada "uberização" indica, de antemão, a orientação a ser seguida pelo juiz na identificação dos elementos fáticos. Há nítida direção do conteúdo decisório a partir do introito configurador da "uberização". Mesmo antes da fundamentação jurídica, o juiz escolhe conceitos prévios que orientam a sua interpretação do contexto probatório.

Nesse aspecto, interessante é a comparação realizada por Engisch entre a verificação de fatos feitas em um processo judicial e àquelas feitas pelos historiadores:

O historiador é livre na utilização das fontes ao seu dispor e na investigação dos fatos, que nela se funda. Ele apenas está vinculado a diretivas científicas. Pelo contrário, a indagação processual da verdade é juridicamente regulada numa larga medida. ${ }^{63}$

59 BRASIL. Diário Eletrônico da Justiça do Trabalho Nacional: Caderno Judiciário do Tribunal Regional do Trabalho da $3^{a}$ Região. Publicação Eletrônica, 14 fev. 2017. n. 2169/2017, 2017, p. 9.

60 MÜLLER, Friedrich. Metódica Jurídica e Sistema Político: Elementos de Teoria Constitucional II. Organização: Rodrigo Meyer Bornholdt, tradução: Michael Kosubek. 1. ed. Joinville: Bildung Editora, 2014, p. 96.

61 MÜLLER, Friedrich. Metódica Jurídica e Sistema Político: Elementos de Teoria Constitucional II, 2014, p. 44.

62 ALEXY, Robert. Teoria da argumentação jurídica: A teoria do discurso racional como teoria da fundamentação jurídica. Tradução: Zilda Hutchinson Schild Silva. 3. ed. Rio de Janeiro: Forense, 2011, p. 210. 
A prerrogativa do juiz, de apreciar livremente o conjunto probatório, está vinculada ao desempenho de uma função estatal que não pode ser arbitrária, pois ainda que haja discricionariedade é um poder cuja competência e extraída das estruturas de poder estatal. A configuração dos elementos diante da confrontação das provas documentais e dos relatos testemunhais servem para formar os elementos de convicção do juiz.

No caso da decisão ora explorada, os elementos de convicção foram formados de forma prévia, pois deixam transparecer que o juiz já havia se posicionado a respeito do assunto e aproveitou o momento da sentença para externar a sua opinião. A posterior avaliação dos elementos fáticos da relação revela um padrão argumentativo consistente no convencimento de que, diante da "uberização", a configuração fática está presente.

Mas é justamente na identificação da subordinação que o magistrado mais se utiliza de sua liberdade criadora na construção da decisão. Fica perceptível a influência ideológica na contextualização livre a partir de constatações pessoais, pois relaciona a identificação da subordinação com a mudança das relações do trabalho derivadas da "uberização". Com a finalidade de ilustrar o que se afirma, destaca-se o seguinte trecho:

$\mathrm{E}$, assim, entramos neste 'admirável mundo novo' no qual os atos humanos de exteriorização do poder diretivo e fiscalizatório não mais se fazem necessários e são substituídos por combinações algorítmicas, reclamando, consequentemente, novas dimensões teóricas e atualizações do Direito do Trabalho para que este importante e civilizatório ramo do direito não deixe passar despercebida a totalizante forma de subordinação e controle construídas dentro de uma forma de flexibilização ${ }^{64}$.

A "uberização", a pós-verdade ${ }^{65}$ (post-truth) e a inovação da organização "uberiana" do "admirável mundo novo" das relações de emprego podem e devem ensejar estudos científicos capazes de fomentar mudanças na legislação e na jurisprudência que alberguem o contexto fático dessa mudança social.

O problema consiste em sustentar todo o critério de interpretação com base em uma identificação pessoal da realidade social. Conforme explica Müller ${ }^{66}$, a pré-compreensão individual é alimentada decisivamente a partir de representações supraindividuais sobre a norma e a matéria e só

64 BRASIL. Diário Eletrônico da Justiça do Trabalho Nacional: Caderno Judiciário do Tribunal Regional do Trabalho da $3^{\text {a }}$ Região. Publicação Eletrônica, 14 fev. 2017. n. 2169/2017, 2017, p. 25.

65 "A sociologia tem usado a expressão 'pós-truth' (pós-verdade) para designar os processos contemporâneos de moldagem de opinião pública. Situações pelas quais os apelos emocionais e o universo dos afetos manipulados pelas apuradíssimas técnicas do marketing constituem-se como "verdades" e passam a ter mais influência e confiabilidade do que o mundo da realidade dos fatos objetivamente considerados.". (BRASIL. Diário Eletrônico da Justiça do Trabalho Nacional: Caderno Judiciário do Tribunal Regional do Trabalho da $3^{\text {a }}$ Região. Publicação Eletrônica, 14 fev. 2017. n. 2169/2017, 2017, p. 29). 


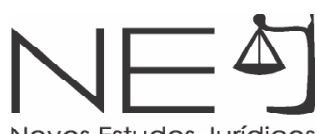

quando racionalizada e diferenciada no âmbito do possível será a concretização controlável.

Ademais, pelo princípio da isonomia, é essencial assegurar a igualdade na relação jurídica processual e a relação processual trabalhista não estaria livre dessa observância. Inclui-se no princípio da isonomia a percepção de equilíbrio da igualdade quando houver desproporção de oportunidades capaz de evidenciar a situação de desigualdade.

Segundo Müller ${ }^{67}$, as cláusulas de igualdade e as proibições de discriminação são as mais importantes normas do sistema político, pois obrigam os funcionários do direito a um trabalho metódico igualitário na legislação, no executivo e na justiça. Trata-se do direito fundamental à igualdade de método, uma pretensão jurídica à igualdade de realização do direito, "garantida por uma metódica correta e aberta no contexto de todas as funções e formas de agir estatal." 68 .

No contexto de uma decisão jurídica, a importância do princípio da vinculação ou adstrição ao pedido limita o poder decisório do juiz e valida a relação jurídica processual decidida, pois cabe ao juiz decidir o mérito diante dos pedidos e da causa de pedir exposta pelo autor como resultado do exercício do contraditório e da ampla defesa efetivamente proporcionada às partes.

Assim, qualquer exclusão ou inclusão metodicamente incorreta de possibilidades de solução do caso jurídico mediante a utilização de interesses ou posições extrajurídicas viola as normas de direito material e processual aplicáveis ao caso ${ }^{69}$.

Parece ter sido esta a hipótese ora avaliada. Ainda que o juiz tenha observado regras processuais quanto ao procedimento, como a instrução processual, na construção de sua sentença preocupouse em fundamentar suas posições extrajurídicas responsáveis pela fundamentação da sua decisão. A identificação dos elementos fáticos da relação de emprego se tornaram meras coadjuvantes diante da "uberização", pois o magistrado teria chegado ao resultado independentemente da confirmação fática de tais elementos.

Nesse aspecto, as palavras de Alexy exemplificam bem as ideias expostas: "os juristas podem certamente contribuir para a realização da razão e da justiça, mas não podem fazer isso sozinhos. Isto pressupõe uma ordem social racional e justa."70.

67 MÜLLER, Friedrich. Metódica Jurídica e Sistema Político, 2014, p. 103.

68 MÜLLER, Friedrich. Metódica Jurídica e Sistema Político, 2014, p. 104.

69 MÜLLER, Friedrich. Metódica Jurídica e Sistema Político, 2014, p. 104.

70 ALEXY, Robert. Teoria da argumentação jurídica, 2011, p. 286. 


\section{CONSIDERAÇÕES FINAIS}

É fundamental que a decisão jurídica seja pautada em critérios seguros, identificados no ordenamento jurídico. Diante de casos difíceis e da necessidade de concretização de Direitos Fundamentais a construção da decisão a partir de uma metodologia pré-determinada evita o solipsismo judicial e situa a decisão jurídica como resultado de uma atividade democrática.

No intuito de "fazer a coisa certa" ou proporcionar a "máxima efetividade dos princípios constitucionais", há falha ao se deixar seduzir pelo chamado "bom ativismo". Mas é preciso ter em mente que esse mesmo raciocínio que possibilita concretizar a Constituição, pode ser utilizado no futuro para sustentar ideia em sentido contrário, derivada de outro critério metajurídico.

É certo também que o direito deve receber influxos da sociologia e da filosofia na construção e atualização de um ordenamento jurídico democrático, mas há de se considerar que a ciência do processo foi desenvolvida com o intuito de impor regras capazes de estabelecer limitações às arbitrariedades do poder estatal ao mesmo tempo que possibilita a concretização do acesso à justiça.

Conforme visto, no caso em estudo o magistrado percorreu o caminho do procedimento trabalhista, mas deixou de atentar que é o devido processo legal que deve guiar a formação de sua convicção, ademais, se o juiz já inicia o processo decidido, não haveria sentido em percorrer o caminho processual.

A fixação da "uberização" como premissa comprova que o juiz se sustenta em ideologia alheia ao debate processual capaz de influenciar na dinâmica do procedimento. Ao iniciar a demanda com a ideia de verdade a respeito da causa, ainda que favorável a um bem constitucionalmente protegido - no caso, os Direitos Fundamentais do trabalhador —, o magistrado utiliza o procedimento para colher provas capazes de fundamentar seus critérios decisórios. Desse modo, qualquer que fossem os elementos-fáticos da relação de emprego indicados pela lei, certamente se encontraria uma argumentação necessária capaz de fundamentar a decisão.

A postura ativista do juiz é realçada na aplicação de elementos ideológicos para "contextualizar" a decisão com o intuito de concretizar a ideia de justiça pré-determinada, formada mediante uma observação individualizada da realidade social, desvirtuando-se das escolhas democráticas identificadas no ordenamento jurídico.

Ainda que a aplicação do Direito mediante critérios técnicos e metodológicos proporcione segurança jurídica e previsibilidade do Direito, esse não deve ser o único objetivo do Direito no constitucionalismo contemporâneo. Tão pouco deve servir de argumento único para críticas ao protagonismo judicial.

A preocupação deve ser no sentido do solipsismo e da desvinculação aparente da função jurisdicional com a estrutura de poder. Decidir é um dever-poder de todos os juízes, mas para fazê-lo 


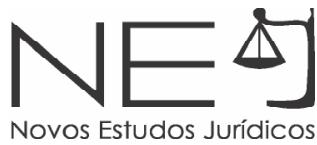

democraticamente necessitam estar a par de seu papel como poder estatal. Há nítida vinculação na discricionariedade decisória do juiz: às leis, ao processo e à Constituição.

Não se defende aqui o retorno ao positivismo jurídico ou a permanência da ideia de supremacia da lei, mas enfatiza-se que o momento atual do pós-positivismo não determina superação do que o positivismo já proporcionou, de modo que não há fim do Estado de Direito.

Portanto, o desafio que se impõe é realizar a justiça mediante o devido processo legal, pois equilibrar a concretização de direitos em cada caso concreto e conforme as regras processuais exige respeito ao método e à estrutura do processo como um instrumento da atividade jurisdicional. Este é o ponto de equilíbrio que deve ser enfrentado na solução das demandas, especialmente em demandas inéditas, como no caso em análise.

\section{REFERÊNCIAS DAS FONTES CITADAS}

AGRA, Walber de Moura. Neoconstitucionalismo e superação do positivismo. Direitos Humanos Fundamentais e as Constituições brasileiras. In: Constitucionalismo social: estudos em homenagem ao Ministro Marco Aurélio de Farias Mello, São Paulo: Editora LTR, 2003.

ALEXY, Robert. Teoria dos Direitos Fundamentais. Tradução: Virgílio Afonso da Silva. 2. ed.4. tiragem. São Paulo: Malheiros editores, 2015.

ALEXY, Robert. Teoria da argumentação jurídica: A teoria do discurso racional como teoria da fundamentação jurídica. Tradução: Zilda Hutchinson Schild Silva. 3. ed. Rio de Janeiro: Forense, 2011.

BARROSO, Luís Roberto; BARCELLOS, Ana Paula. O começo da história: a nova interpretação constitucional e o papel dos princípios no Direito Brasileiro. In: Revista latino-americana de estudos constitucionais. $\mathrm{n}$. 2. Belo Horizonte: Del Rey, 2003. jul-dez. p. 175-210.

BARROSO, Luís Roberto. Neoconstitucionalismo e constitucionalização do direito: o triunfo tardio do Direito Constitucional no Brasil, In: Revista da Procuradoria Geral do Estado do Rio Grande do Sul, v. 28, n.60, Porto Alegre: 2004.

BRASIL. Tribunal Regional do Trabalho da 3a Região. Acórdão no 1704111803811100000013742875. Recorrente: Uber do Brasil LTDA.. Recorrido: Rodrigo Leonardo Silva Ferreira. Relator: Desembargadora Maria Stela Álvares da Silva Campos. Belo Horizonte, MG, 23 de maio de 2017. Diário Eletrônico da Justiça do Trabalho Nacional: Caderno Judiciário do Tribunal Regional do Trabalho da $3^{a}$ Região. Publicação Eletrônica, 25 maio 2017. n. 2234/2017, p. 1154. Disponível em: <https://dejt.jt.jus.br/dejt/f/n/diariocon>. Acesso em: 28 jun. 2017.

BRASIL. Tribunal Regional do Trabalho da $3^{a}$ Região. Sentença nº 17013114275439000000038127039, 33ª Vara do Trabalho. Autor: Rodrigo Leonardo Silva Ferreira. Réu: Uber do Brasil Tecnologia LTDA. Réu: Uber do Brasil Tecnologia LTDA.. Relator: Juiz Márcio Toledo Gonçalves. Belo Horizonte, MG, 13 de fevereiro de 2017. Diário Eletrônico da Justiça do Trabalho Nacional: Caderno Judiciário do Tribunal Regional do Trabalho da $3^{a}$ Região. Publicação Eletrônica, 14 fev. 2017. n. 2169/2017, p. 1721-1741. Disponível em: <https://dejt. jt.jus.br/dejt/f/n/diariocon>. Acesso em: 28 jun. 2017.

BRASIL. Lei n 13.105, de 16 de março de 2015. Código de Processo Civil. Brasília, DF 
CANOTILHO, José Joaquim Gomes. Direito Constitucional e teoria da constituição. 7. ed. 4. reimpr. Coimbra: editora Almedina, 2003.

CAPPELLETTI, Mauro. O Controle judicial de constitucionalidade das leis no direito comparado. Trad. Aroldo Plínio Gonçalves. 2. ed. Porto Alegre: Sergio Antonio Fabris Editor, 1992.

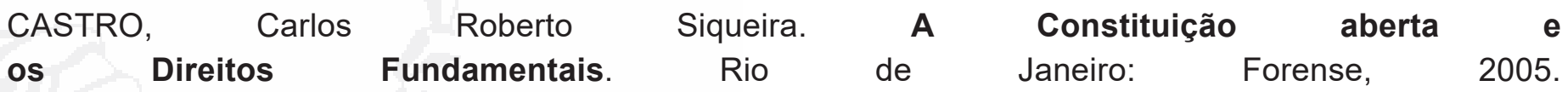

DEBRUYNE, Nicholas L. Uber Drivers: A disput employment relationship in light of the sharing economy. In: Chicago-Kent Law Review. n. 92. Chicago: 2017, p. 289-316. Disponível em: < http://heinonline.org>. Acesso em: 24 de agosto de 2017.

DUARTE, Écio Oto Ramos; POZZOLO, Susanna. Neoconstitucionalismo e Positivismo Jurídico: as faces da Teoria do Direito em tempos de interpretação moral da Constituição. São Paulo: Landy Editora, 2010.

DINAMARCO, Cândido Rangel. A instrumentalidade do processo. 12. ed. São Paulo: Malheiros editores, 2005.

DWORKIN, Ronald. Justice for hedgehogs. Estados Unidos da América: The Belknap Press of Harvard University, 2013.

ENGISCH, Karl. Introdução ao pensamento jurídico. Tradução: J. Baptista Machado. 10. ed. Lisboa: Fundação Calouste Gulbenkian, 2008, p. 127-128.

FISS, Owen. The law as it could be. Estados Unidos da America: New York Universty Press, 2003.

FERRAJOLI, Luigi. Democracia y Garantismo: edicíon de Miguel Carbonell. Coleccíon estructuras y processos: serie derecho. Editorial Trotta, Madrid, 2008.

GALVÃO, Jorge Octávio Lavocat. O neoconstitucionalismo e o fim do Estado de Direito. São Paulo: Saraiva, 2014.

ISAAC, Mike; SINGER, Natasha. California says Uber driver is employee, not a contractor. The New York Times, New York, 17/06/2015, Technology. Disponível em: https://www.nytimes.com/2015/06/18/business/ uber-contests-california-labor-ruling-that-says-drivers-should-be-employees.html. Acesso em: 23 de maio de 2017.

INC., Uber Technologies. Driving jobs vs. Driving with Uber. Disponível em: <https://www.uber.com/ driver-jobs/>. Acesso em: 23 maio 2017.

MÜLLER, Friedrich. Metódica Jurídica e Sistema Político: Elementos de Teoria Constitucional II. Organização: Rodrigo Meyer Bornholdt, tradução: Michael Kosubek. 1. ed. Joinville: Bildung Editora, 2014, p. 96.

MÜLLER, Friedrich. O novo paradigma do Direito: Introdução à teoria e metódica estruturantes. 2. ed. revista, ampliada, atualizada. São Paulo: Revista dos Tribunais, 2009.

STRECK, Lenio Luiz. Jurisdição constitucional e decisão jurídica. 4. ed. São Paulo: Editora Revista dos Tribunais, 2014. 
OSBORNE, Hilary. Uber loses right to classify UK drivers as self-employed. The Guardian, London, 28/10/2016, Technology. Disponível em: <https://www.theguardian.com/technology/2016/oct/28/uber-uktribunal-self-employed-status>. Acesso em: 23 de maio de 2017.

POSEN, Hannah A. Ridesharing in the sharing economy: Should regulators impose über regulations on Uber? In: Iowa Law Review. v.101, n. 405. lowa: 2015, p. 405-434. Disponível em: < http://heinonline.org>. Acesso em: 24 de agosto de 2017.

Recebido em: 11/08/2020

Aprovado em: 17/12/2020

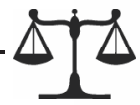

